\title{
Fighting against malaria: prevent wars while waiting for the "miraculous" vaccine
}

\author{
Jose G. Montalvo \\ Department of Economics, \\ Universitat Pompeu Fabra \\ and IVIE*
}

\author{
Marta Reynal-Querol ${ }^{\dagger}$ \\ Department of Economics (UPF) \\ and The World Bank
}

\begin{abstract}
The World Health Organization estimates that 300 million clinical cases of malaria occur annually and observed that during the 80's and part of the 90's its incidence increased. In this paper we explore the influence of refugees from civil wars on the incidence of malaria in the refugee-receiving countries. Using civil wars as an instrumental variable we show that for each 1,000 refugees there are between 2,000 and 2,700 cases of malaria in the refugee receiving country. On average $13 \%$ of the cases of malaria reported by the WHO are caused by forced migration as a consequence of civil wars.
\end{abstract}

JEL classification number: I18, I31, O15.

\footnotetext{
*Instituto Valenciano de Investigaciones Economicas

${ }^{\dagger}$ We thank J. Caballe, M. Reiter, A. Cabrales, participants in the European Economic Association Meetings (Venice 2002) and the Vancouver Conference (2004) "Deadly connections: the war-disease nexus" for many useful comments. We are also very grateful for the valuable comments of two anonymous referees and the editor (Daron Acemoglu). Financial support from the IVIE and the Ministerio de Ciencia y Tecnologia (SEC2004-03619 for Montalvo and SEC2003-04429 for Reynal Querol) is kindly acknowledged. Jose G. Montalvo thanks the hospitality of the Poverty Group of the Research Department (DECRG) of the World Bank, where most of the revision of this paper was done.
} 


\section{Introduction.}

With the number of clinical cases of malaria on the rise, reaching some 300 million a year, there is increasing concern over the economic and public health burden of this disease. Over 90 countries suffer from the incidence of malaria and some $36 \%$ of the world's population live in areas of risk of transmission. Malaria causes around 2 million deaths worldwide, a large proportion of those being children in sub-Saharan Africa $^{1}$.

There are two predominant views with respect to the incidence of malaria. The first one, represented by J. Sachs, and also expressed in some reports from the World Health Organization, is that malaria is basically determined by the ecological conditions of the tropics ${ }^{2}$. The second view is that economic, social and political institutions have a very important influence on the incidence of malaria ${ }^{3}$. It is not clear therefore, to what extent malaria has an important effect on the country's income or the correlation between the incidence of malaria and income reflects the reverse causality of income on malaria. The current paper re-examines this particular issue and finds evidence of a large increase in malaria prevalence in response to social disruption and migration due to civil wars.

During the last decades many civil conflicts have taken place in areas where malaria is a major public health concern. The forced migration caused by those

\footnotetext{
${ }^{1}$ For instance in the Kilombero Valley (Tanzania) half of all deaths are children younger than one year. See Schellenberg et al (2001). Sachs and Malaney (2002) report that 2,000 children die of malaria each day.

${ }^{2}$ Paul Reiter (quoted by Budiansky 2002), a medical entomologist at the US Center for Disease Control notes that "we associate malaria with the tropics only because we've forgotten- because we've relegated malaria to the tropics." In fact many areas of North America and Europe have important populations of efficient malaria vectors.

${ }^{3}$ In the first edition of Bruce-Chwatt's reference book on malaria (1978) the emphasis is placed on epidemiological causes. It is noticeable the change in the general vision of the problem from the first to the second edition (1985)where the author emphasizes the effect of adverse social and economic conditions, due to internal difficulties. In the economic literature the current debate between Sachs (2003), McArthur and Sachs (2001) and Acemoglu et al. (2001) is a vivid example of this controversy.
} 
conflicts has led to a significant increase in the transmission of malaria in areas, that for a long time have been considered, of low risk. In fact $29 \%$ of the world's population "live in areas where malaria was once transmitted at low level or not at all but where significant transmission has been reestablished". ${ }^{4}$

Recently Ghobarah, Huth and Russett (2001) have found that the burden of death and disability incurred in 1999 from the indirect effect of civil wars in the period 199097, is equal to the direct effect of wars during 1999. In this paper we also study the health consequences of civil wars beyond the direct causalities. These effects span beyond the war period and the country that suffered the conflict. We analyze the effect of forced migration and, in particular, refugees from civil wars, on the incidence of malaria in the refugee receiving countries. As far as we know this is the first attempt to measure this relationship from a macro perspective and using panel data ${ }^{5}$. We find that refugees coming from a country with a high incidence of malaria, have an important impact on the incidence of malaria in the refugee-receiving country. Our estimation suggests that for each 1,000 refugees from a malaria endemic country involved in a civil war, there are between 2,000 and 2,700 new cases of malaria in the refugee-receiving country.

The paper is organized as follows: In section 2 we analyze the nexus between malaria and forced migration, with special emphasis on the impact of civil wars. Section 3 describes the basic econometric specification and the sources of data. In section 4 we present the results of the estimation and discuss several robustness tests. In particular we report the sensibility of the results in considering only African countries, to instrumental variables estimation and also to changes in the frequency of the data (from yearly to five years averages). Section 5 contains a discussion of the

\footnotetext{
${ }^{4}$ Bloland and Williams (2003).

${ }^{5}$ Other contributions have considered only a particular, and normally very small, geographical area and a short time period.
} 
relative importance of refugees from civil wars in the explanation of the total cases of malaria. Finally, in section 6 we present the conclusions.

\section{Malaria and forced migration}

In general malaria transmission depends on the dynamics of the relationship between men, vector, parasite and environment. Malaria transmission is not widespread in densely populated urban areas $^{6}$. The outbreak of a civil war or an important social conflict very often generates the movement of people fleeing from its consequences. If there is risk of malaria transmission in the country, even if it is small, and the vector is present, so then forced migration is a likely cause for a serious public health concern. There are many reasons for the increase in malaria incidence as a consequence of forced migration. First of all, most of the population that flee from urban areas is generally not immune to malaria. Secondly malaria incidence is high in rural areas where the vector can live longer in a favorable environment. Also the anarchic situation caused by this social unrest and the military importance on paved roads, force people to walk through unfamiliar rural areas, dumps and forests in order to avoid areas of military activity, so actually helping facilitate its incidence. In fact population movement (due to political conflicts or civil wars) is potentially the most important factor in the transmission of malaria (conditional on the dynamics between vector, parasite and environment $)^{7}$.

The contact of a non-immune individual with an immune rural population in a high risk area, also increases the risk of transmission. The importance of contact with immune individuals is critical because repeated infection amongst individuals of rural endemic areas generates an immune response in the host, who controls the infection. This fact implies that amongst the rural population, the prevalence of

\footnotetext{
${ }^{6}$ In some tropical cities the existence of large slums facilitates the transmission of malaria.

${ }^{7}$ See for instance Curtin $(1989,1998)$ and Cruz Marques (1987).
} 
malaria could be very high, but with only a small number of reported cases. Even without reinfection, the persistence of the malaria parasites could last from two years (Plasmodium falciparum) to four years (Plasmodium vivax) or even up to as many as 50 years (Plasmodium malariae). However the risk of life threatening malaria is exclusively borne by non-immune populations ${ }^{8}$. Paradoxically it is in low endemicity areas where the risk of severe infection is highest among the adult population, because they may grow up without developing immunity. Moreover, migrants in general would not carry nets, tents or other protective devices and, therefore, they are even more exposed to the vector. War also generates the collapse of health care infrastructure. In addition private shows and pharmacies close down during wars, further restricting the access to antimalarial drugs. The displaced population often reallocates near water sources, which is dangerous since water is also the breeding site for mosquitoes. In addition to these in rural areas there is livestock that may attract mosquitoes which may also feed on people.

Apart from these factors, it is also the case that the population that live in rural areas with a high risk of malaria has different degrees of immunity with respect to their time exposure to malaria ${ }^{9}$. The contact of a population which moves from an area of high transmission to an area of low transmission also raises the likelihood of a large increase in malaria incidence. Finally, the area of origin and the area of destination may be quite different in terms of the prevalence of drug-resistant malaria. This implies that, even if other people in the area of destination take anti-malarial drugs their efficiency may be affected by the drug resistant malaria of migrants. Notice also that even if an effective anti-malarial drug was available, there would be serious complications over its distribution in areas suffering from civil wars or a high degree of social conflict.

\footnotetext{
${ }^{8}$ Najera et al. (1992).

${ }^{9}$ Immunity to malaria is reduced over time in the absence of exposure.
} 
For all these reasons, forced migration is very likely to be the source of an important increase in the incidence of malaria. Not only that, many civil wars take place in countries with a high incidence of malaria. It is well known ${ }^{10}$ that malaria was the primary cause of mortality among Cambodian refugees that arrived to eastern Thailand in 1979. The same was true for adult Mozambican refugees in Malawi and Ethiopian refugees in eastern Sudan. The annual incidence of malaria among the refugees fleeing Myanmar and going to western Thailand was 1,037 cases per thousand ${ }^{11}$. The five years civil war in Tajikistan led to the reemergence of malaria in an area that had been malaria free for many years. Malaria is still a major problem among forced migrants in the Democratic Republic of Congo, Ethiopia and Guinea.

We argue then that civil wars and social conflict are a basic source of the observed increase in the incidence of malaria, either directly (i.e. non-immune refugees get in contact with infected individuals when they flee through rural and rainforest areas, to reach a foreign country) or indirectly (i.e. civil wars make it very difficult or even impossible to keep active control measures against malaria). Notice that if this is the case the problem of creating more effective drugs against malaria, is not only the economic cost for developing countries of making it available to the population, but also the fact that frequent civil wars in developing countries will make its administration very difficult. In fact it could also become an "weapon" for some of the factions involved in a civil war. Therefore, as in the case of control efforts, the effectiveness of the new drugs ${ }^{12}$ will depend not only on socioeconomic development

\footnotetext{
${ }^{10}$ Glass et al. (1980).

${ }^{11}$ This estimate is smaller than our estimates for the total effect of malaria. The reader should also notice that it refers to an Asian country. The basic vector in Africa (Anopheles gambiae) is much more efficient in the transmission of malaria than the vectors in Asia (for instance the Anopheles stephensi or the culicifacies) .

${ }^{12}$ The recent completion of the DNA map of the Plasmodium parasite (Gardner et al. 2002) and the Anopheles gambiae (Holt et al. 2002) open some new hopes for the future of antimalarial drugs and even vaccines. However the prediction of Najera et al. (1992) is valid for the future: "Even if vaccines, new drugs, or new insecticides are developed, in view of the time required for their final testing in the field, it is difficult to expect a significant impact on malaria for a long time".
} 
and the incentives for vaccine research but also on political stability.

[Insert figure 1 around here]

Figure 1 presents a general view of the relationship between the official data on cases of malaria and civil wars. With respect to the total cases of malaria it should be borne in mind that the number of reporting countries varies over time. In particular there are two countries that have a determinant influence on the number of cases: China and India. China started to report officially to the World Health Organization (WHO) in 1977. Initially it reported close to four million cases but from 1977 onwards it reported an exponentially decreasing number of cases. India is also an important case in terms of its effect on the total number of cases. For this reason in Figure 1 we also depict the relationship between the number of civil wars and the cases of malaria in the world, without counting India and China. Still after eliminating the influence of India and China there exists the problem of the African region. The countries in this area are known to have irregular reports, in many cases due to the difficulties caused by sociopolitical conflicts. For this reason we have performed an interpolation procedure $^{13}$ to attribute for the missing data of these countries. The interpolation is performed using the latest available data before the missing period and the first available figure, once reporting resumes. In this way if the incidence reporting was stopped because of a civil war and the number of malaria cases rose during the war period then the initial figure of the next reporting period would incorporate most of the increase in malaria.

[Insert figure 2 around here]

Figure 2 represents the total cases of malaria obtained using this interpolation procedure and the number of refugees worldwide. The high correlation of these variables is one of the motives for this research on refugees and the incidence of malaria.

\footnotetext{
${ }^{13}$ We use the ipolate function of STATA in order to apply an standard procedure instead of using our own criterion.
} 
Obviously the increase in the incidence of malaria cannot only be the result of "tropical destiny" since this is invariant over time. There must be a combined effect of ecological and non- ecological factors which explain this tendency. Amongst them we argue that the interaction between civil wars and tropical location is one of the basic factors.

\section{Econometric specification and data sources.}

In this section we discuss the basic determinants of malaria incidence and data sources. For the purpose of finding the determinants of malaria we use the basic arguments proposed by Najera et al. (1992), who distinguished different patterns of reported malaria cases. The so called "group B", which generates most of the cases, includes "countries characterized by either recent efforts to increase the exploitation of natural resources (through agricultural colonization of forest or jungle areas) or by civil war and sociopolitical conflict (including illegal drug trade) and large movements of refugees or other mass migrations" (Najera 1992).

Our basic regression has the following form

$$
M A L_{j t}=\theta_{j}+\beta X_{j t}+\gamma Z_{j t}+u_{j t}
$$

where $M A L$ is the number of new cases of malaria in the refugee-receiving country, $X$ contains a measure of the refugees in country $j$ and $Z$ includes the variables of the refugee-receiving country that may have an effect on the number of cases of malaria and a yearly dummy variable. The determinants of malaria incidence included in the regressions follow the factors cited by Najera et al (1992), Sachs and Malaney (2002) and Bloland and Williams (2003). There are basically two groups of factors: ecological conditions and social conditions. The ecological conditions include the African savannah, the plains and valleys outside of Africa, the highlands, seashore and 
coastal areas. All these geographical conditions are country specific but time invariant and, therefore, are included in the "country specific effect", of our regression. The individual effect, $\theta_{j}$ represents also the difference in the reporting practices among countries, if they are stable over time. For instance, it is well documented that in many African countries the cases of malaria are usually counted as clinically diagnosed cases instead of laboratory confirmed ones. However the availability of a panel data of countries helps to disentangle these effects, if reporting practices do not change too much over time ${ }^{14}$.

The social conditions which affect malaria incidence include the agricultural colonization of forest, the construction of refuse tips and irrigation systems, the migrant agriculture labor force, the worsening of the health system and the displacement of population. We proxy these social factors with data on the extension of land irrigation, the percentage of rural population, the number of physicians per thousand population, and the incidence of civil wars and natural disasters. These variables are grouped in $Z$. We include the displaced populations, in different versions, in the $X$ variable. Table 1 presents the summary statistics for the main variables in the specification, which are described below.

\subsection{Malaria incidence}

Data on the number of diagnosed malaria cases come from WHO. From 1982 to 1997 the data was reported in the Weekly Epidemiological Record. From 1962 to 1981 the data was published in the World Health Statistics Annual (1983). The values represent the number of malaria cases reported by countries and the WHO regional offices during the period 1962-1997. Whilst this is the most reliable information on malaria incidence, the WHO points out that for Africa, the figures refer only

\footnotetext{
${ }^{14}$ From this section on we use the original data, without the interpolation we considered in the previous section for aggregation purposes, jointly with methods of estimation apropriate for incomplete panel data.
} 
to clinically diagnosed cases (except for the North African countries, Cape Verde, Djibouti, Mauritius, Reunion, Somalia and South Africa). The figures from the other continents represented are mostly laboratory confirmed cases.

There are 162 countries that have reported cases of malaria between 1962 and 1997. In 27 of those countries the cases of malaria were imported by tourists that travelled to tropical countries. Because of the purpose of our study we are not going to consider these cases, which correspond basically to the OECD countries. Therefore our final sample includes 135 countries.

\subsection{Geographical variables}

The dummy variable for tropical country comes from the Global Development Network Growth database (GDNG). The original source of this reference is the Global Demography Project ${ }^{15}$, which considers that a country is tropical if the absolute value of the latitude of the quadrilateral ${ }^{16}$ that contains the largest number of people in the country is less than or equal to 23,5 degrees (between the Tropic of Cancer and the Tropic of Capricorn). In our sample we have 103 tropical countries.

\subsection{Refugees}

There are two basic sources of information for the data on refugees: the United Nations High Commission for the Refugees (UNHCR), and the US Committee For Refugees (USCR). The data on refugees that we use comes from the United Nation High Commission for the Refugees. This data is publicly available only from 1993 until 1999. Thanks to Susanne Schemeidl we have had access to the internal data of the UNHCR from 1951 until 1999 ${ }^{17}$. Following the UNHCR definition, refugees are

\footnotetext{
${ }^{15}$ Tobler et al. (1995). See also http://www.ciesin.org/dataset/gpw/globldem.doc.html.

${ }^{16}$ The total number of polygons, generated by the grid used by the Project, that cover the world is 19,032. The population of the countries was assigned to five minutes by five minutes quadrilaterals.

${ }^{17}$ The data from 1951 to 1992 is not public and come from the work of Schemidl and Jenkins (2001). We are indebted to them for providing us this data, which is not publicly available. Schemidl
} 
persons recognized as refugees under the 1951 United Nations Convention relating to the Status of Refugees or its 1967 Protocol, the 1969 Organization of African Unity (OAU) Convention Governing the Specific Aspects of Refugee Problems in Africa, persons recognized as refugees in accordance with the UNHCR Statute, persons granted humanitarian or comparable status and those granted temporary protection. This dataset is organized by country of origin and country of asylum and provides information on the number of refugees that arrive to the asylum country at time $t$ coming from different origin countries.

Internally Displaced (IDPs) are persons who are displaced within their country. The data on IDPs collected by the UNHCR is very scarce and only provides information on IDPs where they provide assistance to them. We also have information on IDPs from the USCR which is the only systematic data base for internal displacement that exists. However, it only covers very few years. Because of these shortcomings, the use of this variable is very problematic and, consequently, we decided to work only with refugees and not with internally displaced people.

\subsection{Civil Wars}

The data on civil wars come from Doyle and Sambanis (2000) (DS), which involves as part of the definition an intensity indicator. This definition is nearly identical to the definition of Singer and Small $(1982,1994)$.

\subsection{Natural Disasters}

Data on Natural Disasters comes from the EM-DAT: The OFDA/CRED International Disaster Database ${ }^{18}$. Since 1988 the WHO collaborating Centre for Research on and Jenkins (2001) also describe the difference between the data compiled by the UNHCR and the USCR. They argue that the data from the UNHCR have higher quality than the ones coming from the USCR.

${ }^{18}$ EM-DAT: The OFDA/CRED International Disasater Database- www.cred.be/emdat-Universite Catholique de Louvain-Brussels-Belgium. 
the Epidemiology of Disasters (CRED), has been maintaining an Emergency Events database EM-DAT. EM-DAT was created with the initial support of the WHO and the Belgian Government.

The disasters database contains essential data on the occurrence and effects of mass disasters in the world from 1900 to the present day. The disaster data are sub-divided into three types: natural, technological and conflicts. EMDAT contains essential core data on the occurrence and effects of over 12.500 mass disasters in the world from 1900 to present. The database is compiled from various sources, including UN agencies, non-governmental organizations, insurance companies, research institutes and press agencies. The OFDA/CRED offers information on the occurrence, the number of people injured, killed, made homeless and the total number affected.

There are many different types of natural disasters included in the data base: drought, earthquake, extreme temperature, flood, landslide, volcano, tidal wave, wildfire and windstorm. From all these natural disasters we are only interested in the ones that imply mass movements of people. One situation that cause mass migration with very high probability is drought and its main consequence, famine. Droughts usually have a lengthy duration and cannot be handled easily without moving to other areas.

\subsection{Health data}

We also control for the extension of the health system in each country. The health data comes mainly from the World Development Indicators of the World Bank. We consider the number of hospitals beds per 1000 population and the number of physicians per 1000 population $^{19}$. These two variables are highly correlated. Data on hospitals beds is available from 1970, and data of physicians is available from 1965 . Before 1985, the information on hospitals beds and physicians was basically collected

\footnotetext{
${ }^{19}$ We also considered using the access that rural population has to the health system, but this information is only available for a few number of countries and only from 1983 until 1993.
} 
every five years $(1965,1970,1975,1980$ and 1985). Only for some countries is there any yearly data. Since information on hospitals beds is more scarce than information on physicians and they have a high correlation, we decided to use the number of physicians per thousand inhabitants as the explanatory variables. Since the number of hospitals beds and the number of physicians move smoothly we have interpolated the data on the number of physicians in order to avoid a large reduction in the sample size. $^{20}$

\subsection{Other variables}

Data on the hectares of land irrigated (IRRIG) and the proportion of rural population (RURAL) comes from the World Development Indicators. We also use in our estimation the proportion of each country's area where there is risk of malaria transmission (MCID). The last variable comes from the Center for International Development (CID) at Harvard University. It represents the percentage of land area in each country affected by Anopheles species calculated in equal-area cylindrical projection. From some comments in Gallup and Sachs (2000) we believe that the original information of the CID data on the land area affected by Anopheles species come from four digitalized maps: for 1946 the map in Pampana and Russell (1955); for 1966 the source is WHO (1967); for 1982 the source is WHO (1984); and for 1994 the source is WHO (1997). We construct the variable MCID by merging these data. Before 1967 we use the data for 1946; after 1966 and before 1982 we use the data corresponding to 1967; after 1981 and before 1994 we use the information for 1982; and, finally, after 1993 we use the data for 1994.

\footnotetext{
${ }^{20}$ From 3.214 observations to only 789 observations. Montalvo and Reynal-Querol (2002) show that using the interpolated series produce very similar results to the ones obtained using the noninterpolated variable.
} 


\section{Empirical results}

Taking into account the previous considerations the econometric specification

$$
\begin{aligned}
M A L_{j t}= & \theta_{j}+\beta R E F_{j t}+\gamma_{1} R U R A L_{j t} \\
& +\gamma_{2} \text { PHYS }_{j t}+\gamma_{3} I R R I G_{j t}+\gamma_{4} D R_{j t} \\
& +\gamma_{5} C W_{j t}+\gamma_{6} M C I D_{j t}+u_{j t} \\
R E F_{j t}= & \sum_{i \neq j} R E F_{i j t}
\end{aligned}
$$

where MAL represents the new cases of malaria in the refugee-receiving country $j$ at time $t, R E F_{i j t}$ are the refugees of country $i$ to country $j^{21}$ at time $t$, RURAL is the proportion of rural population in the refugee-receiving country, PHYS is the number of physician per thousand inhabitants in the refugee-receiving country and IRRIG is the land irrigated area, also in the refugee-receiving country. Since the data on internally displaced population is very scarce we include a dummy for drought (DR), another for civil war $(\mathrm{CW})$ and the percentage of population that lives with the risk of malaria transmission (MCID). All three variables refer to the refugee-receiving country and try to capture the determinants of the likelihood and the intensity of movement of population inside the refugee-receiving country. We also include a set of yearly dummy variables to consider possible time effects. Rapid urbanization, and therefore the reduction of the proportion of rural population, of marginal areas within cities is usually done in an uncontrolled way which leads to poor quality housing, lack of proper drainage and inadequate vector borne disease control. These conditions lead to an exponential growth of mosquito vectors and increase exposure to them. Therefore we expect RURAL to have a negative effect on malaria incidence. A high

\footnotetext{
${ }^{21}$ The results for the proportion of population infected with respect to total population and refugees per capita are qualitatively the same as the ones that appear in the tables. See Montalvo and Reynal-Querol (2002).
} 
proportion of physicians (PHYS) per thousand inhabitants should also have a negative effect on malaria given that it represents a good health system and the possibility of improved prevention. The proportion of land irrigated (IRRIG) should have a positive effect because of two reasons. First of all the increase of water surfaces favors the proliferation of mosquito larvae. Second this variable is also a proxy for agricultural colonization of new areas. Droughts (DR) and civil wars (CW) in the refugee-receiving country will also favor the displacement of people and, therefore, should increase the incidence of malaria ${ }^{22}$ through the slackening of preventative measures and the other mechanisms discussed in the previous section. MCID should obviously have a positive effect on the incidence of malaria.

Table 2 presents the results of these basic regressions using all the observations (tropical and non tropical destination countries). The sample covers the period from 1962 until 1997. The estimates are obtained by using the fixed effects estimator for unbalanced panel data ${ }^{23}$. In the first column we can observe that the total number of refugees does not have an effect on the malaria cases in the refugee-receiving country, while the proportion of rural population and physicians per inhabitant have, as expected, a negative effect. The area of irrigated land however, does has a positive and significant effect. Whilst the dummies of drought and civil war in the refugeereceiving country have no significant effect on malaria incidence. Finally the variable MCID has a positive and significant effect on malaria.

Table 2, columns 2 to 3 present the results of aggregating the refugees by specific characteristics of the country of origin (REFO). The new variable REFO computes as refugees coming from a tropical country $(\mathrm{O}=\mathrm{TR})$ or from a tropical country with

\footnotetext{
${ }^{22}$ If the data on internally displaced had a larger temporal and spatial coverage than they have we could have used them instead of the natural disaster and civil war dummies.

${ }^{23} \mathrm{We}$ do not use the interpolated data for refugees and malaria incidence. We only used the interpolation to construct the aggregate figures we presented in the previous section. To facilitate the reading of the tables the coefficients of the dummy variables and RURAL, PHYS and MCID have been divided by 10.000 .
} 
a civil war $(\mathrm{O}=\mathrm{TR}+\mathrm{CW})^{24}$. Therefore

$$
R E F O_{j t}=\sum_{i \neq j} O_{i} * R E F_{i j t}
$$

where $O_{i}$ is a dummy that takes value 1 if refugees come from a country $i$ that have the specific characteristic considered in each column (tropical or tropical and civil war). In the second column the variable REFO refers to refugees going to country $j$ from a tropical country. In this case the coefficient is significantly different from 0 and higher than 1 . The rest of the variables have the expected sign and, with the exception of DR and CW, they are significantly different from 0 . The results are even stronger if we constrain the variable REFO to reflect, only refugees coming from tropical countries where there is a civil war (column 3).

Columns 4 to 6 of table 2 present the same regressions but using the sample of tropical destination countries. In this case all the refugees, independently from their origin, have a significant effect on the incidence of malaria. In column 6 though, the coefficient increases dramatically if the origin of the refugees is a tropical country with a civil war. In this case 1,000 refugees generate 1,406 cases of malaria in the refugeereceiving country. Another interesting and expected result, is the lost of statistical significance of MCID. This implies that the percentage of population that live with the risk of malaria transmission is irrelevant if we work only with tropical destination countries.

Table 2 shows a very strong and consistent story. The estimated coefficients of the variables have the predicted sign and the size of the coefficient on refugees increases monotonically in the right direction. In fact the only situation in which refugees are shown not to have any impact on the incidence of malaria is when there is no vector to transmit the illness: that is to say refugees do not come, or do not go, to a tropical

\footnotetext{
${ }^{24}$ The previous version of this paper (Montalvo and Reynal-Querol 2002) considers also separately the refugees from civil wars.
} 
country.

\subsection{Robustness check I: Africa versus the rest of the world}

Are these results brought about by specific countries or areas? The results of the estimations show that the degree of impact of civil war refugees on the incidence of malaria in the refugee-receiving country depends on the tropical nature of the origin country and the destination one. However, as we expressed before, there are problems of irregular data collection on the incidence of malaria in African countries. The problem of irregular reporting is not important as the estimation of incomplete panel data does not present any particular econometric difficulty. The most important difference with respect to reporting cases of malaria between African countries and the rest of them is the fact that in Africa cases are counted on a clinically diagnosed basis $^{25}$ while in other countries they consider confirmed cases of malaria (through blood analysis). China is an exception to this, as not all cases are confirmed by laboratory diagnosis. Therefore the reporting procedure varies across countries. We assume that the method of determining a patient with malaria and the intensity of "counting" cases of malaria in each country is stable over time. However, if that were not the case, the ratio of physicians per inhabitant would compensate for it because the clinically diagnosed cases should be recognized by a specialist. From our estimation it seems that the preventative effect of physicians is larger than the increase in the intensity of counting, if there is any such effect.

Nevertheless, in order to perform robustness checks, in columns 1 to 3 of table 3 we include the results of the estimation of the tropical countries but without all African countries. The regressions distinguish, as previously done so, between total refugees, those refugees coming from a tropical country or those refugees from a

\footnotetext{
${ }^{25}$ Except for the North African countries, Cape Verde, Mauritius, Reunion, Somalia and South Africa that report laboratory confimed cases.
} 
tropical country that are suffering a civil war. Columns 1 confirms that total refugees do not have any explanatory power on the incidence of malaria. Column $2(\mathrm{O}=\mathrm{TR})$ shows that refugees coming from a tropical country have a significantly positive effect on the incidence of malaria in the refugee receiving country, even if we eliminate Africa. The results in column 3 confirm the findings of previous columns: refugees coming from a tropical country with a civil war have a larger effect on malaria than the refugees only coming from tropical countries. Just as we were expecting the size of the coefficient is much smaller than in the case of the samples that include the African countries. However, notice that the high transmission rates in sub-Saharan Africa reflect the enormous efficiency of Africa's main vector, the Anopheles gambiae, due mostly to its tendency towards biting human beings. ${ }^{26}$. Finally, columns 4 to 6 of table 3 report the results of the same estimation using only African countries. As in previous regressions the refugees coming from a tropical country involved in a civil war have a positive and significant effect on the cases of malaria. Since our sample includes African countries this coefficient is much larger than the coefficient obtained in column 3, as expected.

\subsection{Robustness check II: Instrumental variables estimation (IV)}

In the previous section we have considered refugees as an exogenous variable. However there maybe reasons to argue that the number of refugees maybe endogenous to the incidence of malaria. Therefore we should find an instrument for the number of refugees in order to obtain a consistent estimator for the regressions.

We consider two possible instruments. The first one is a civil war in the countries of origin of the refugees. The identifying assumption in this case would be, that civil wars generate refugees and do not have a direct effect on malaria in other countries.

\footnotetext{
${ }^{26}$ Garrett-Jones and Shidrawi (1969).
} 
We believe that this is a plausible hypothesis. However civil wars in the refugee's country of origin maybe correlated with some unobservable factors that affect the refugee-receiving country and are not included in the regression ${ }^{27}$. For this reason we consider a second instrument: the predicted number of refugees. We constructed a model to explain bilateral refugees using some particular geographic characteristics (distance between countries, sizes, etc.). The identifying assumption in this case is that geographical characteristics are not correlated to the residual of the main regression ${ }^{28}$. So then, we use the predicted number of refugees as an instrument for the actual number of refugees ${ }^{29}$. Therefore, there may be other factors that affect the incidence of malaria in the refugee receiving country but, since our instrument is constructed using geographical characteristics, there is no reason to expect that they will be correlated with the same instrument. The econometric specification for the (log) number of refugees is the following

$$
\begin{aligned}
\ln R E F_{i j}= & \alpha_{1}+\alpha_{2} \ln D_{i j}+\alpha_{3} \ln P_{i}+\alpha_{4} \ln A_{i} \\
& +\alpha_{5} L_{i}+\alpha_{6} B_{i j}+\alpha_{7} B_{i j} \ln D_{i j} \\
& +\alpha_{8} B_{i j} \ln P_{i}+\alpha_{9} B_{i j} \ln A_{i}+\alpha_{10} B_{i j} L_{i}+\epsilon_{i j}
\end{aligned}
$$

where $R E F_{i j}$ is the number of refugees from country $i$ (origin) to country $j$ (destination), $D_{i j}$ is the distance between $i$ and $j, P_{i}$ is the population of the country of origin, $A_{i}$ is the area, $L_{i}$ is a dummy for landlocked country and $B_{i j}$ is a dummy for common border countries. As in Frankel and Romer (1999) we also include the

\footnotetext{
${ }^{27}$ However, notice that from the first regression we include as an explanatory variable the dummy for civil war in the refugee-receiving country. Therefore if the civil war in the country of origin of the refugee spreads to the refugee-receiving country and this is the only link between both, then the estimator using the civil war instrument will be consistent.

${ }^{28}$ We obviously do not use any geographic characteristic related with latitud or longitude which would be correlated with the residual.

${ }^{29}$ See Frankel and Romer (1999) for an application of this strategy to the estimation of the effect of trade on growth.
} 
interaction of all the variables with the variable borders. Distance is measured as the great-circle distance between countries' principal cities. Rand McNally (1993) is used as the source for the size of the country, common borders and landlocked countries. The data on population comes from the World Development Indicators.

The results of this regression are presented in table 4 and coincide with what anyone would have expected. The distance between two countries is negatively related with the number of refugees, whilst sharing a common border has a large and positive effect on the number of refugees. The result of being landlocked by border is also statistically significant and has a positive effect: having a common border increases the number of refugees in landlocked countries. Finally the size of population in the origin country has a positive effect, if it has a common border with the refugee receiving country. The $\mathrm{R}^{2}$ of the regression is 0.27 . The correlation between $\log$ of the predicted and actual refugees is 0.52 .

After estimating that regression, we calculate the predicted number of refugees going to country $j$ by adding up the predicted refugees going to a particular country and coming from all the other countries. Since the regression is in logs the number of predicted refugees to country $j$ is

$$
\widehat{R E F} F_{j}=\sum_{i \neq j} \exp \left(\widehat{\alpha}^{\prime} W_{i j}\right)
$$

where $W$ contains all the explanatory variables $\left(\ln D_{i j}, \ln P_{i}, \ln A_{i}, L_{i}, B_{i j}\right)$ and the cross products with B.

In table 5 we present the results of the estimation of the panel using these two instruments: civil wars (CW) and predicted refugees (PREF), in the case of tropical destination countries. As in table 2 we consider all the refugees and refugees from tropical countries. The standard deviation of the regressions are calculated as in any instrumental variables estimation. The fact that we are using generated instruments does not affect the standard error of the IV regression, since under the condition 
that $E(u \mid X)=0$ the asymptotic standard errors and the test statistics are still asymptotically valid ${ }^{30}$. The estimation in table 5 shows that the effect of refugees on the incidence of malaria in the refugees-receiving countries is positive and significantly different from 0 . In fact it is higher than in the non-instrumented case. The use of civil wars, column 1, or predicted refugees, column 2, do not make much of a difference. Columns 3 and 4 show the estimation using as an explanatory variable, the refugees from a tropical country. As in the first two columns the estimated coefficient for refugees is larger than in the non-instrumented panel data estimation and the choice of instrument has a minor effect on the estimation. In addition, as shown also in table 2, the estimated coefficient for refugees from a tropical origin is higher than the one corresponding to refugees of any country.

\subsection{Robustness check III: changing the frequency}

One possible problem, with the fixed effect panel data estimation presented in the previous sections, is the existence of serial correlation in the data. We could try to estimate the model including some hypothesis about the form of that autocorrelation. However, the fact that there is frequently missing data, complicates that simple experiment. For these reasons (possibility of autocorrelation and frequent missing data) we have run the previous regression at a higher level of time aggregation. Table 6 presents the same regressions as table 2 but using five year averages instead of yearly data. The estimates are remarkably similar. Perhaps the only exception is the estimated coefficient for refugees from tropical countries suffering a civil war, which is clearly higher than in table 2 . It is also interesting to note that the variable MCID, which was significantly different from 0 in table 2 , turns out to be statistically

\footnotetext{
${ }^{30}$ Frankel and Romer (1999) correct the usual variance covariance matrix of the IV coefficients claiming that the instruments depend on the parameters of an estimated regression. This argument is not correct for the case of generated instruments, although it would be correct for generated regressors (see for instance Wooldridge 2002).
} 
insignificant when using five year averages.

Are the results of the instrumental variables regressions affected then by the change in frequency of the data? Table 7 presents the IV regressions of table 5 but using the five year averages data instead. The results follow the pattern previously discussed for the case of yearly data. The IV estimator for the coefficient on refugees increases with respect to the one obtained in table 6 but less than in the case of yearly data. For this reason the estimates of that coefficient using yearly data or five years averages are closer in the IV estimation than in the standard fixed effect estimation, in particular when we restrict our attention to the refugees that come from tropical countries.

\section{Geography versus dislocation}

The relationship between disease and development has recently attracted a lot of attention $^{31}$. However the negative effect of malaria on growth has been recognized for a long time. Initially the studies on the economic impact of malaria were concerned with the loss of labor input (Ross 1911). However malaria has an important effect even if there is no human loss. Frequent malaria attacks increase school absenteeism ${ }^{32}$ and lost work time. In addition they reduce productivity by affecting work intensity, reducing the scope for specialization and the intensity of workers mobility. The productivity effect however is not only reduced to the agricultural sector. The areas with high incidence of malaria have difficulties promoting tourism and foreign direct investment, suffering also an infrastructure deficit since the cost of construction increases with the likelihood of malaria and the need to invest in protection measures.

\footnotetext{
${ }^{31}$ For a historical perspective see Acemoglu et al. (2003).

${ }^{32}$ Bleakley (2003) uses individual level data to analyze the effect of malaria erradication on school attendance in the South of the United States between 1900 and 1950. Miguel and Kremer (2004) show evidence of the effect of the hookworm and other infectious diseases on schooling using randomized experiments.
} 
Using the estimates of the previous section we can calculate the proportion of malaria cases that can be attributed to geography and poverty versus the dislocation caused by civil wars. We can estimate this ratio by dividing the cases of malaria attributed to the refugees caused by civil wars (the average yearly number of refugees from civil wars multiplied by the corresponding parameter estimate) over the fitted values of the regression ${ }^{33}$. Figure 3 presents the evolution of this ratio during the sample period. The average ratio is $13.24 \%$ although it oscillates depending on the beginning or the end of civil wars in tropical areas. It is also interesting to notice that the mean in the period previous to the beginning of the 80 's is smaller than the average for the period post 1980. Figure 3 shows also that the proportion of malaria cases caused by forced migration has decrease drastically in the last few years of the sample.

[Insert figure 3 around here]

Another way to give an idea of the potential impact of refugees from civil wars on the distribution of malaria is to estimate the proportion of the variance of malaria cases accounted for by those refugees. This also serves to demonstrate the potential scope of international interventions targeted at avoiding civil conflicts. The upper bound estimate of the variance accounted for by the forced migration caused by civil wars is the adjusted $R^{2}$ from the linear regression of malaria cases on the refugees from tropical countries in a civil war. For comparison we calculate a lower bound as the increase in the adjusted $R^{2}$ when the refugees from tropical countries in a civil war are added to a regression that contains the country dummies and the MCID variable (proportion of area of the country at risk of malaria transmission). The upper bound estimate reaches $9.2 \%$ while the lower bound is $4.7 \%$.

\footnotetext{
${ }^{33}$ This procedure is just an approximation since there may be compensations.
} 


\section{Conclusions}

The burden of malaria transmission in the world, especially in underdeveloped countries, is very large in terms of diagnosed cases and deaths. It is estimated that it affects three hundred million people and kills 2 million people every year. Many researchers have found that malaria has a very negative effect on development through its effects on productivity (repeated workers absences on the workplace, reduction of geographical job flexibility, etc.). But it is also the case that economic underdevelopment increases malaria incidence.

Several authors have argued that malaria is basically a result of geographical destiny. However there are efficient vectors in many places outside of the tropics and malaria is not transmitted in those areas. There are also perfectly efficient vectors capable of surviving cold winters. For these reasons even entomologists think that,

in the end, human behavior and economic factors are the most important causes of malaria incidence. Negative socioeconomic conditions can favor the spread of malaria and make the control tasks very difficult. Therefore there are technical factors and social conditions, especially the ones that generate mass migration, which explain the incidence of malaria. Moreover technical factors are also affected by social conditions.

In fact we could talk about two alternative views of malaria: for some researchers malaria is basically a social disease with socioeconomic causes, while for some others malaria is primarily a clinical problem that requires medical research. As the search for a vaccine could last for a long time and the effectiveness of other control measures depend on social conditions, it is reasonable to think about policies that may prevent the basic cause of mass migration: civil wars and social conflicts.

It is true that drug resistance in the Plasmodium parasite and insecticide resistance in the vectors has hindered the attempts to combat the disease. However, we have shown that the size of the refugee population coming from tropical countries with 
civil wars have an important contribution to the number of cases of malaria in the refugee-receiving countries. Our instrumental variables estimates show, that 1,000 refugees generate between 2,000 and 2,770 new cases of malaria in the refugee receiving country. Therefore, the prevention of civil wars, especially in tropical countries, and the control of its causes is very important for the development on the control of malaria. However, more effective control methods will not mean the end of malaria if civil conflicts make its application impossible. An example of a simple device made in the 20th century which was crucial in stopping malaria transmission in Europe and North America was the window screen. Obviously, homeless refugees fleeing from civil wars and walking through forests and dumping sites are not likely to have any protection whatsoever against repeated biting by Anopheles mosquitoes.

Our estimates point out that approximately $13.2 \%$ of the yearly cases of malaria during the period 1962-97 can be attributed to dislocation by contrast with geography or poverty. Therefore any effort to reduce the spread of civil wars and control its causes can help to moderate, at least partially, the extension of malaria transmission and its impact on economic development. 


\section{References}

[1] Acemoglu, D., Johnson, S. and J. A. Robinson (2001), "The Colonial Origins of Comparative Development: an Empirical Investigation," American Economic Review, 91 (5), 1369-1401.

[2] Acemoglu, D., Johnson, S. and J. Robinson (2003), "Disease and development in historical perspective," Journal of the European Economic Association, 1, 2-3, $397-405$.

[3] Bleakley, Hoyt (2003). "Disease and Development: Evidence from the America South", Journal of the European Economic Association, 1(2-3), 376-386.

[4] Bloland, P. and H. Williams (2003), Malaria control during mass population movements and natural disasters, The National Academy Press, Washington.

[5] Bruce-Chwatt, L. (1985), Essential Malariology, John Wiley and Sons, New York.

[6] Budiansky, S. (2002), "Creatures of our own making," Science, 298, 80-86.

[7] Curtin, P. (1989), Death by Migration: Europe's encounter with the Tropical World in the Nineteenth Century, New York, Cambridge University Press.

[8] -_-_-_ (1998), Disease and Empire: The Health of European Troops in the Conquest of Africa, New York, Cambridge University Press.

[9] Cruz Marques, (1987), "Human Migration and the spread of Malaria in Brasil," Parasitology Today, 3: 166-170.

[10] Doyle, Michael W., and Nicholas Sambanis (2000) "International Peacebuilding: A Theoretical and Quantitative Analysis." American Political Science Review 94:4 (December). 
[11] EM-DAT: The OFDA/CRED International Disaster Database, www.cred.be/emdat-Universite Catholique de Louvain-Brussels-Belgium.

[12] Frankel and Romer (1999), "Does trade cause growth," American Economic Review, 89, 3, 379-399.

[13] Gallup, J. and J. Sachs (2001), "The Economic Burden of Malaria," supplement to The American Journal of Tropical Medicine and Hygiene, 64, 1-2, 85-96..

[14] Garrett-Jones, C. and J. R. Shidrawi (1969), "Malaria Vectorial Capacity of a Population of Anopheles Gambiae: an Exercise in epidemiological entomology," Bulletin of the World Health Organization, 40, 531-545.

[15] Ghobarah, H., Huth, P. and B. Russett (2001), "Civil Wars kill and Maim PeopleLong after the Shooting stops," mimeo, Yale University.

[16] Glass, R., Cates, W., Nieburg, P., Davis, C., Russbach, R., Nothdurft, H., Peel, S. and R. Turnbull (1980), "Rapid assessment of health status and preventivemedicine needs of newly arrived Kampuchean refugees to Sa Kaeo (Thailand)," Lancet (8173), 868-872.

[17] Global Development Network Growth Database, GDNG, World Bank.

[18] R. Holt et al. (2002), "The genome sequence of the malaria mosquito Anopheles gambiae," Science, 298, 129-148.

[19] McArthur, J. and J. Sachs (2001), "Comment on Acemoglu, Johnson and Robinson," NBER Working Paper 8114.

[20] Miguel, E. and M. Kremer (2004), "Worms: Education and Health Externalities in Kenya," forthcoming in Econometrica. 
[21] Montalvo, J. G. and M. Reynal-Querol (2002), "Fighting against malaria: prevent wars while waiting for the 'miraculous' vaccine," IVIE Working Paper WPEC 2002-31.

[22] Najera, J., Liese, B. and J. Hammer (1992), "Malaria: New Patterns and Perspectives," World Bank Technical Paper number 183.

[23] Pampana, E. and P. Russell (1995), Malaria, World Health Organization, Geneve.

[24] Rand McNally (1993), Quick reference world atlas, Chicago.

[25] Ross, R. (1911), The Prevention of Malaria, New York: E. P. Dutton.

[26] Sachs, J. (2003), "Institutions don't rule: direct effect of geography on per capita income," NBER WP 9490.

[27] Sachs, J. and Malaney (2002), "The economic and social burden of malaria," Nature, 415, 680-685.

[28] Sachs, J. and J. Gallup (2001), Geographical dataset, Center for International Development (CID).

[29] Schellenberg, D., C. Menendez, E. Kahigwa, J. Aponte, J. Vidal, M. Tanner, H. Mshinda and P. Alonso (2001), "Intermittent treatment for malaria and anaemia control at time of routine vaccinations in Tanzanian infants: a randomized, placebo controlled trial," The Lancet, 357, 1471-1477.

[30] Schmeidl, S. and J. Jenkins (2001), "Global Refugee and Displaced dataset," Mershon Center for International Security, Ohio State University.

[31] Singer, J.D. and M. Small (1982) Resort to arms: International and civil war, 1816-1980. Beverly Hills, CA: Stage. 
[32] Singer, J. D. and M. Small (1994), Correlates of war project: International and civil war data, 1816-1992 (data file; April; ICPSR 9905); Ann Arbor, University of Michigan.

[33] Tobler, W., U. Deichmann, J. Gottsegen and K. Maloy (1995), The Global Demography Project, Technical Report TR-95-6.

[34] WHO (1999), "Malaria 1982-1997," Weekly Epidemiological Record, 13 August 1999, 265-270.

[35] Wooldridge, J. (2002), Econometric Analysis of Cross Section and Panel Data, MIT Press, Cambridge, MA.

[36] World Bank (2000), World Development Indicators 2000.

[37] World Health Statistics Annual, 1983, 791-795. 
Table 1: Summary statistics.

\begin{tabular}{lr}
\hline Variable & \multicolumn{1}{c}{ Mean } \\
\hline Malaria & 173,339 \\
Tropical (dummy) & 0.76 \\
Refugees & 47,937 \\
Civil wars (dummy) & 0.14 \\
Drought (dummy) & 0.09 \\
Physicians per 1000 & 0.55 \\
inhabitants & \\
Proportion rural pop. & 0.60 \\
MCID & 0.59 \\
\hline
\end{tabular}


Table 2: Fixed effects panel data estimation.

\begin{tabular}{lcccccc}
\hline \hline Destination & \multicolumn{3}{c}{ All countries } & \multicolumn{3}{c}{ Tropical countries } \\
\hline Origin (O) & All & TR & TR+CW & All & TR & TR+CW \\
\hline REF & 0.016 & -0.078 & -0.070 & 0.865 & -0.060 & 0.10 \\
REFO & $(0.36)$ & $(-1.63)$ & $(-1.49)$ & $(5.90)$ & $(-0.22)$ & $(0.51)$ \\
& & 1.14 & 1.38 & & 1.30 & 1.41 \\
RURAL & & $(7.15)$ & $(8.35)$ & & $(4.06)$ & $(5.71)$ \\
& -1.62 & -1.45 & -1.43 & -1.75 & -1.68 & -1.65 \\
PHYS & $(-8.65)$ & $(-7.77)$ & $(-7.70)$ & $(-7.58)$ & $(-7.26)$ & $(-7.17)$ \\
& -32.1 & -29.9 & -29.6 & -26.5 & -24.9 & -24.8 \\
IRRIG & $(-5.25)$ & $(-4.94)$ & $(-4.90)$ & $(-3.15)$ & $(-2.97)$ & $(-2.97)$ \\
& 0.038 & 0.037 & 0.037 & -0.008 & -0.008 & -0.007 \\
DR & $(3.94)$ & $(3.86)$ & $(3.83)$ & $(-0.15)$ & $(-0.14)$ & $(-0.13)$ \\
& 3.69 & -8.96 & 2.99 & 2.33 & 1.66 & 3.46 \\
CW & $(0.10)$ & $(0.25)$ & $(0.08)$ & $(0.52)$ & $(0.37)$ & $(0.78)$ \\
& -5.15 & -6.36 & -6.13 & -5.55 & -5.54 & -5.28 \\
MCID & $(-1.42)$ & $(0.76)$ & $(0.71)$ & $(1.14)$ & $(1.14)$ & $(1.10)$ \\
& 1.14 & 1.10 & 1.09 & -1.05 & 0.18 & 0.20 \\
R ${ }^{2}$ & $(2.18)$ & $(2.12)$ & $(2.12)$ & $(0.15)$ & $(0.03)$ & $(0.03)$ \\
Countries & 0.12 & 0.15 & 0.17 & 0.12 & 0.14 & 0.16 \\
N obs. & 104 & 104 & 104 & 72 & 72 & 72 \\
\hline REF refers & 2722 & 2722 & 2722 & 1919 & 1919 & 1919 \\
\hline
\end{tabular}

REF refers to all the refugees. REFO refers to refugees by origin: refugees could be from a tropical country (TR) or a tropical country suffering a civil war $(\mathrm{TR}+\mathrm{CW})$. RURAL is the proportion of rural population. PHYS is the proportion of physicians. DR is a dummy variable for a drought in the refugee receiving country. $\mathrm{CW}$ is a dummy variable for a civil war in the refugee receiving country. MCID is the proportion of each country's area where there is risk of malaria transmission. 
Table 3: Fixed effects panel data estimation.

\begin{tabular}{lcccccc}
\hline \hline Destination & \multicolumn{3}{c}{ Tropical without Africa } & \multicolumn{3}{c}{ Only Africa } \\
\hline Origin $(\mathrm{O})$ & $\mathrm{All}$ & $\mathrm{O}=\mathrm{TR}$ & $\mathrm{O}=\mathrm{TR}+\mathrm{CW}$ & $\mathrm{All}$ & $\mathrm{O}=\mathrm{TR}$ & $\mathrm{O}=\mathrm{TR}+\mathrm{CW}$ \\
\hline REF & 0.00 & -0.02 & -0.01 & 1.13 & 2.22 & 0.11 \\
REFO & $(0.02)$ & $(0.68)$ & $(0.54)$ & $(4.61)$ & $(1.47)$ & $(0.28)$ \\
& & 0.24 & 0.21 & & -1.05 & 1.35 \\
RURAL & & $(2.21)$ & $(1.91)$ & & $(0.70)$ & $(3.29)$ \\
& -0.05 & -0.05 & -0.05 & -2.16 & -2.19 & -2.12 \\
PHYS & $(1.19)$ & $(1.16)$ & $(1.16)$ & $(5.87)$ & $(5.94)$ & $(5.77)$ \\
& 0.49 & 0.64 & 0.61 & -49.27 & -39.86 & -46.26 \\
IRRIG & $(0.41)$ & $(0.53)$ & $(0.51)$ & $(1.95)$ & $(1.53)$ & $(1.84)$ \\
& 0.06 & 0.05 & 0.05 & 0.26 & 0.27 & 0.33 \\
DR & $(8.63)$ & $(7.77)$ & $(7.98)$ & $(0.70)$ & $(0.74)$ & $(0.89)$ \\
& -0.65 & -0.58 & -0.56 & 2.21 & 2.26 & 4.42 \\
CW & $(0.75)$ & $(0.67)$ & $(0.65)$ & $(0.30)$ & $(0.31)$ & $(0.60)$ \\
& 2.72 & 2.64 & 2.62 & -1.30 & -1.18 & -1.21 \\
MCID & $(3.75)$ & $(3.63)$ & $(3.61)$ & $(1.04)$ & $(1.27)$ & $(1.32)$ \\
& 3.43 & 3.38 & -0.49 & -7.23 & -7.06 & -6.99 \\
R ${ }^{2}$ & $(1.06)$ & $(1.04)$ & $(0.54)$ & $(0.41)$ & $(0.40)$ & $(-0.40)$ \\
Countries & 0.12 & 0.13 & 0.13 & 0.07 & 0.08 & 0.09 \\
N obs. & 35 & 35 & 35 & 44 & 44 & 44 \\
\hline REF refers & 1091 & 1091 & 1091 & 1023 & 1023 & 1023 \\
\hline
\end{tabular}

REF refers to all the refugees. REFO refers to refugees by origin: refugees could be from a tropical country (TR) or a tropical country suffering a civil war $(\mathrm{TR}+\mathrm{CW})$. RURAL is the proportion of rural population. PHYS is the proportion of physicians. DR is a dummy variable for a drought in the refugee receiving country. $\mathrm{CW}$ is a dummy variable for a civil war in the refugee receiving country. MCID is the proportion of each country's area where there is risk of malaria transmission. 
Table 4. Predicting refugees by geography

\begin{tabular}{lc}
\hline \hline & Variables \\
\hline Ln Distance & -0.20 \\
& $(-13.2)$ \\
Ln Population & 0.01 \\
(country i) & $(1.28)$ \\
Ln Area & 0.00 \\
(country i) & $(0.35)$ \\
Landlocked & 0.01 \\
(country i) & $(0.44)$ \\
Border & 5.33 \\
& $(7.05)$ \\
Border*Ln Distance & -0.66 \\
& $(-6.65)$ \\
Border*Ln Population & 0.13 \\
& $(2.37)$ \\
Border*Ln Area & 0.03 \\
& $(0.52)$ \\
Border*Landlocked & 2.17 \\
& $(13.57)$ \\
Constant & 1.62 \\
& $(10.3)$ \\
R2 & 0.27 \\
F & 527 \\
$\mathrm{~N}$ & 12,998 \\
\hline
\end{tabular}


Table 5. Instrumental variables estimation.

\begin{tabular}{lcccc}
\hline \hline Destination & \multicolumn{3}{c}{ Tropical destination countries } \\
\hline Origin & \multicolumn{2}{c}{ All the countries } & \multicolumn{2}{c}{ Tropical countries } \\
\hline Instrument & CWI & PREF & CWI & PREF \\
\hline REF & 1.97 & 2.03 & 2.66 & 2.77 \\
& $(2.80)$ & $(2.84)$ & $(2.80)$ & $(2.84)$ \\
RURAL & -1.49 & -1.51 & -1.36. & -1.36 \\
& $(5.28)$ & $(5.18)$ & $(4.32)$ & $(4.20)$ \\
PHYS & -2.19 & -2.19 & -1.91 & -1.88 \\
& $(2.44)$ & $(2.34)$ & $(2.04)$ & $(1.93)$ \\
IRRIG & -0.04 & -0.06 & -0.04 & -0.06 \\
& $(0.76)$ & $(0.99)$ & $(0.72)$ & $(0.94)$ \\
DR & 1.09 & 1.01 & 2.07 & 3.80 \\
& $(0.24)$ & $(0.21)$ & $(0.04)$ & $(0.93)$ \\
CW & -7.27 & -7.35 & -7.13 & -7.32 \\
& $(1.44)$ & $(1.35)$ & $(1.41)$ & $(1.35)$ \\
MCID & -2.76 & -3.02 & -1.13 & -2.43 \\
& $(0.39)$ & $(0.41)$ & $(0.02)$ & $(0.03)$ \\
F (first stage) & 24.21 & 23.49 & 22.09 & 21.27 \\
Countries & 72 & 68 & 72 & 68 \\
N obs. & 1919 & 1823 & 1919 & 1823 \\
\hline
\end{tabular}

REF refers to all the refugees. RURAL is the proportion of rural population. PHYS is the proportion of physicians. DR is a dummy variable for a drought in the refugee receiving country. $\mathrm{CW}$ is a dummy variable for a civil war in the refugee receiving country. MCID is the proportion of each country's area where there is risk of malaria transmission. Column CWI contains the results of the estimation using as an instrumental variable the existence of a civil war in any origin country. PREF uses also the predicted number of refugees. F is the F-statistic of the first stage regression. 
Table 6: Five years averages. Fixed effect panel data regressions.

\begin{tabular}{lcccccc}
\hline \hline Destination & \multicolumn{3}{c}{ All countries } & \multicolumn{3}{c}{ Tropical countries } \\
\hline Origin $(\mathrm{O})$ & All & TR & TR+CW & All & TR & TR+CW \\
\hline REF & 0.05 & -0.07 & -0.10 & 1.02 & -0.12 & -1.17 \\
& $(0.47)$ & $(0.63)$ & $(0.94)$ & $(3.22)$ & $(2.51)$ & $(-1.90)$ \\
REFO & & 1.09 & 1.83 & & 1.34 & 2.38 \\
& & $(3.28)$ & $(4.58)$ & & $(2.51)$ & $(4.10)$ \\
RURAL & -2.15 & -1.97 & -1.83 & -2.20 & -2.15 & -2.00 \\
& $(5.16)$ & $(3.28)$ & $(4.53)$ & $(4.42)$ & $(4.33)$ & $(4.08)$ \\
PHYS & -4.92 & -4.67 & -4.53 & -4.12 & -4.01 & -3.73 \\
& $(3.38)$ & $(3.24)$ & $(3.17)$ & $(2.02)$ & $(1.97)$ & $(-1.87)$ \\
IRRIG & 0.02 & 0.02 & 0.01 & -0.04 & -0.03 & -0.02 \\
& $(0.84)$ & $(0.81)$ & $(0.75)$ & $(0.29)$ & $(0.24)$ & $(0.22)$ \\
DR & 2.09 & 1.26 & 1.32 & 3.71 & 3.64 & 4.30 \\
& $(1.30)$ & $(0.79)$ & $(0.83)$ & $(1.92)$ & $(1.88)$ & $(2.26)$ \\
CW & -1.32 & -1.27 & -0.77 & 3.38 & 1.17 & 3.11 \\
& $(0.14)$ & $(0.13)$ & $(0.08)$ & $(0.03)$ & $(0.09)$ & $(0.25)$ \\
MCID & 1.21 & 1.20 & 1.18 & -4.24 & -2.54 & -1.75 \\
& $(0.96)$ & $(0.97)$ & $(0.95)$ & $(0.26)$ & $(0.15)$ & $(0.11)$ \\
R-sq & 0.14 & 0.19 & 0.21 & 0.11 & 0.12 & 0.18 \\
Countries & 104 & 104 & 104 & 72 & 72 & 72 \\
N obs. & 630 & 630 & 630 & 451 & 451 & 451 \\
\hline REF refers & & &
\end{tabular}

REF refers to all the refugees. REFO refers to refugees by origin: refugees could be from a tropical country (TR) or a tropical country suffering a civil war $(\mathrm{TR}+\mathrm{CW})$. RURAL is the proportion of rural population. PHYS is the proportion of physicians. DR is a dummy variable for a drought in the refugee receiving country. $\mathrm{CW}$ is a dummy variable for a civil war in the refugee receiving country. MCID is the proportion of each country's area where there is risk of malaria transmission. 
Table 7: Instrumental variables: five years averages

\begin{tabular}{lcccc}
\hline Destination & \multicolumn{4}{c}{ Tropical countries } \\
\hline Origin & \multicolumn{2}{c}{ All countries } & \multicolumn{2}{c}{ Tropical countries } \\
\hline Instrument & CWI & PREF & CWI & PREF \\
\hline REF & 2.34 & 2.36 & 2.70 & 2.71 \\
& $(1.98)$ & $(2.24)$ & $(1.94)$ & $(2.30)$ \\
RURAL & -1.82 & -1.86 & -1.75 & -1.78 \\
& $(3.01)$ & $(3.10)$ & $(2.78)$ & $(2.78)$ \\
PHYS & -3.39 & -2.41 & -3.20 & -3.21 \\
& $(1.55)$ & $(1.51)$ & $(1.45)$ & $(1.41)$ \\
IRRIG & -0.07 & -0.10 & -0.05 & -0.09 \\
& $(0.54)$ & $(0.71)$ & $(0.44)$ & $(0.61)$ \\
DR & 2.43 & 2.46 & 2.34 & 2.37 \\
& $(1.07)$ & $(1.05)$ & $(1.02)$ & $(1.00)$ \\
CW & 1.17 & 2.61 & 2.82 & 4.23 \\
& $(0.09)$ & $(0.19)$ & $(0.22)$ & $(0.31)$ \\
MCID & -5.64 & -6.05 & -2.16 & -2.51 \\
& $(0.33)$ & $(0.35)$ & $(0.13)$ & $(0.15)$ \\
Countries & 72 & 68 & 72 & 68 \\
\hline $\mathrm{N}$ & 451 & 451 & 451 & 451 \\
\hline
\end{tabular}

REF refers to all the refugees. RURAL is the proportion of rural population. PHYS is the proportion of physicians. DR is a dummy variable for a drought in the refugee receiving country. $\mathrm{CW}$ is a dummy variable for a civil war in the refugee receiving country. MCID is the proportion of each country's area where there is risk of malaria transmission. Column CWI contains the results of the estimation using as an instrumental variable the existence of a civil war in any origin country. PREF uses also the predicted number of refugees. 
Figure 1. Cases of malaria and civil wars.

Source: WHO Weekly Epidemiological Record (1999) and Doyle and Sambanis (2000).

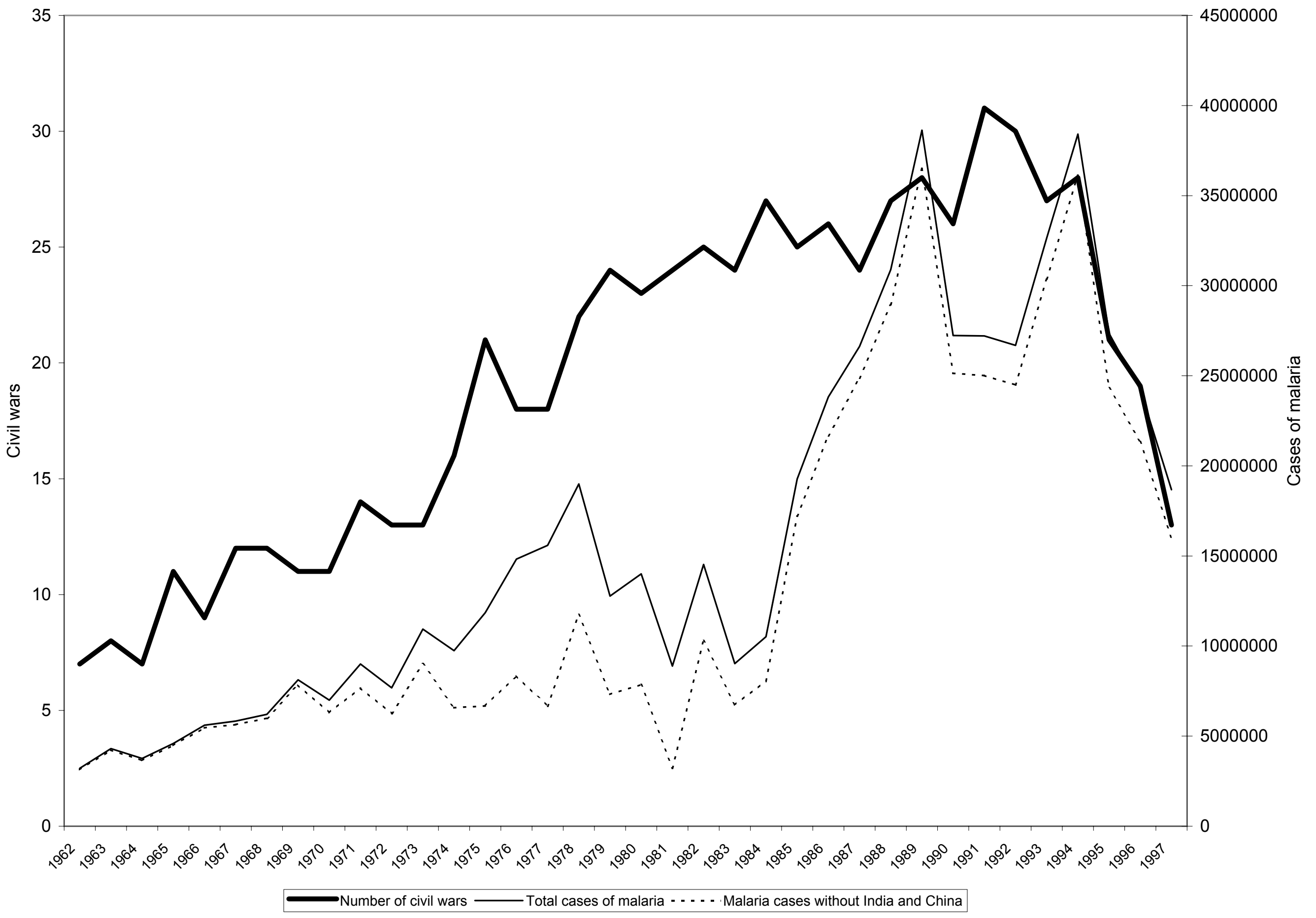


Figure 2. Refugees and cases of malaria.

Sources: UNHCR and Weekly Epidemiological Record (1999).

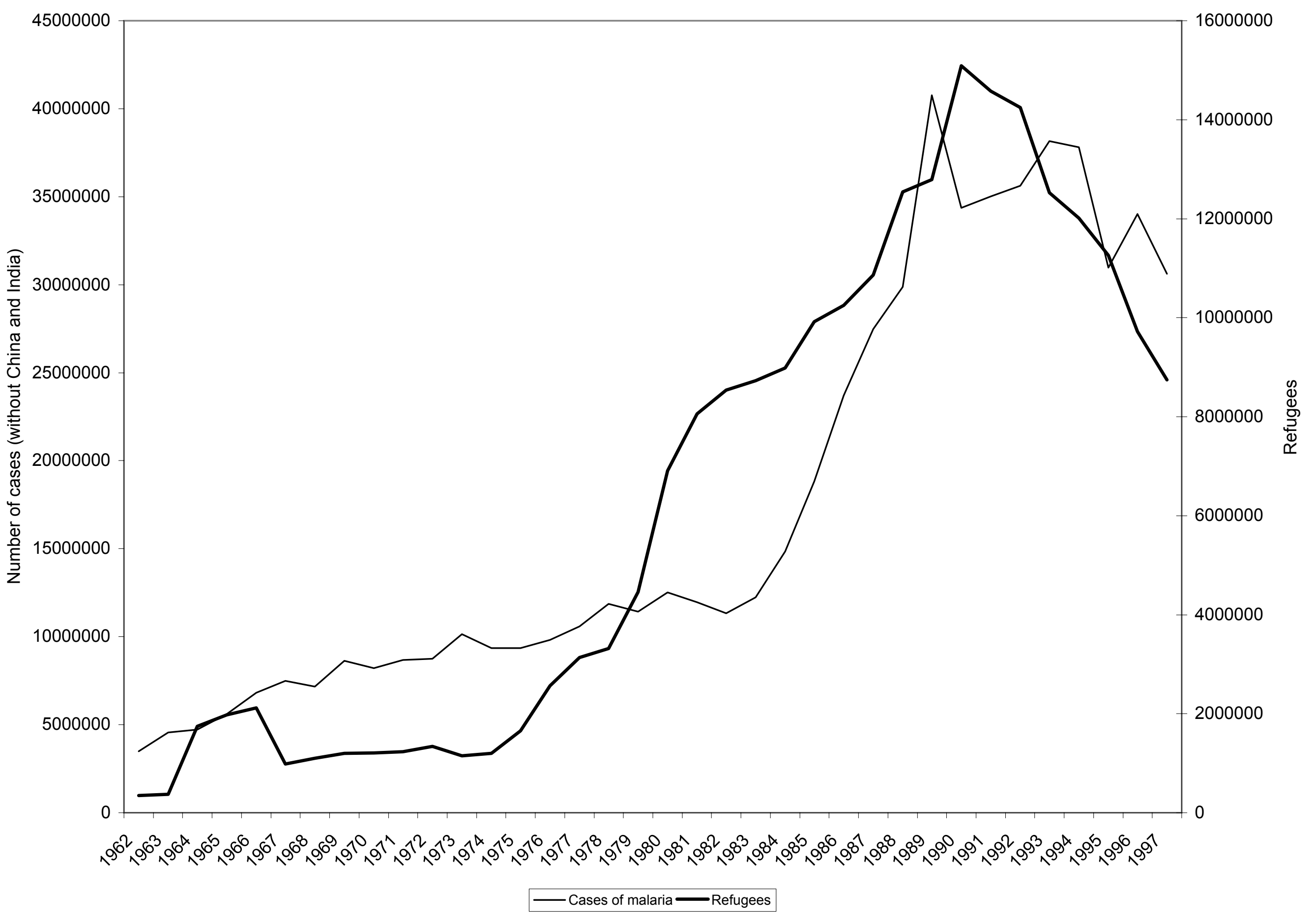


Figure 3. Proportion of malaria cases explained by refugees from civil wars over total cases. Yearly estimates.

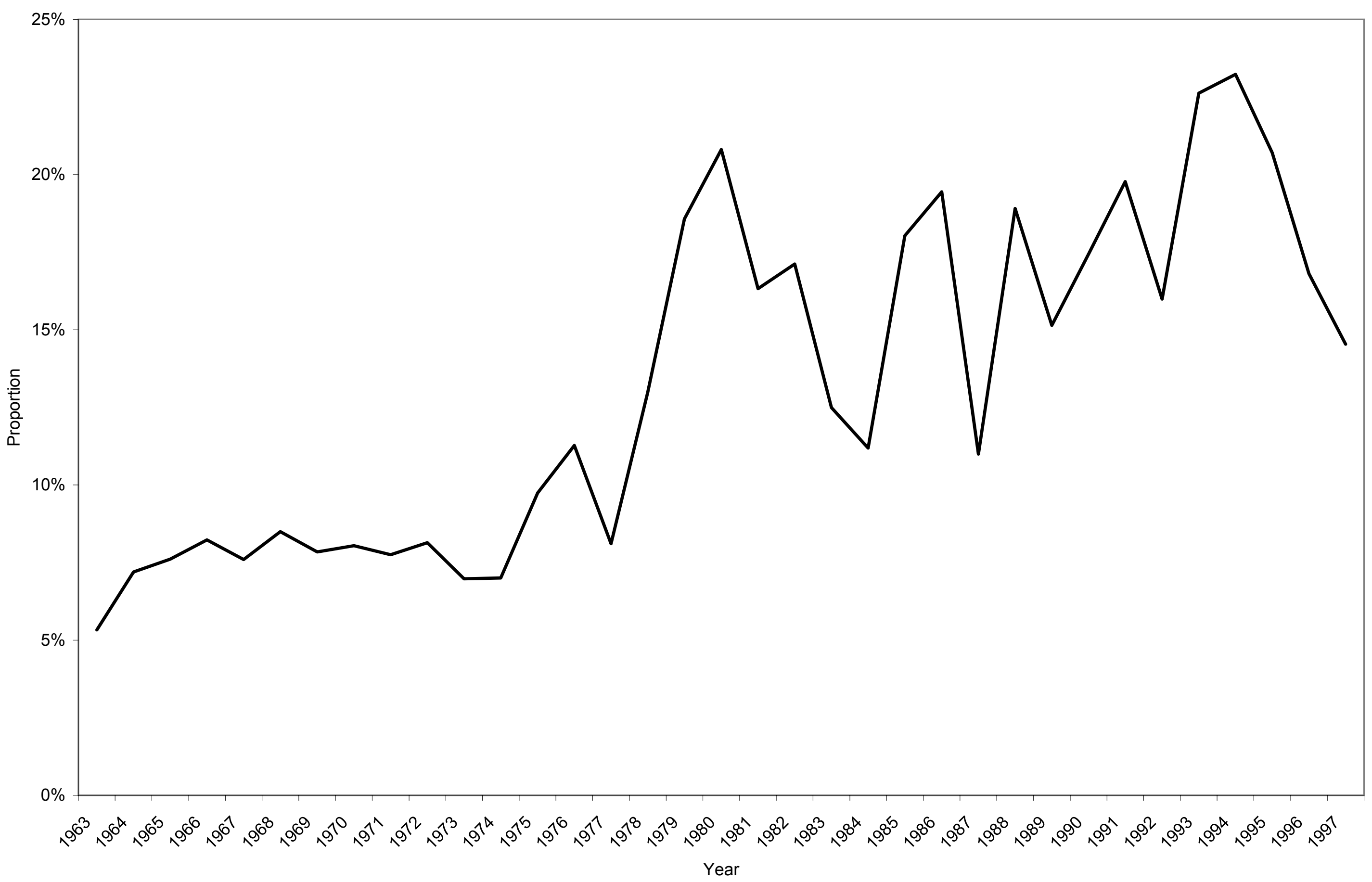

